\title{
Effect of Saw Type Corrugated Pipe on Laminar Convective Heat Transfer by Using SiC-Water Nanofluid: A Numerical Study
}

DOI:10.36909/jer.12803

\author{
Md Insiat Islam Rabby*, Farzad Hossain**, M M Raihan***, Afrina Khan Piya***, Riyazul \\ Kabir Rhythm**** and M Mustafa Kamal***** \\ *Department of Mechanical and Manufacturing Engineering, Universiti Putra Malaysia, \\ Serdang 43400, Selangor, Malaysia \\ **Department of Mechanical and Production Engineering, Islamic University of Technology, \\ Gazipur 1704, Bangladesh \\ ***Department of Mechanical Engineering, University of Leeds, Leeds, United Kingdom \\ ****Jamuna Gas, Dhaka 1212, Bangladesh \\ *****Bangladesh Army University of Engineering and Technology, Bagatipara, Qadirabad \\ Cantoment, Natore 6431, Bangladesh \\ *Corresponding Author: insiatislam8@gmail.com
}

\begin{abstract}
Enhancing the heat transfer rate is highly required to remove excessive heat load from the heat transfer apparatus, which may cause massive damage to the equipment. Thus, increment of heat transfer area is one of the prime solutions for this issue. The increment of heat transfer area can be done by enhancing the pipe wall and incorporating nanoparticles with working fluids because nanoparticles showed much faster heat dispersion due to a vast surface area for heat transfer and increased thermal conductivity. Also, small molecules of nanoparticles are allowed for free movement and thus micro-convection, promoting high thermal conductivity. Higher thermal conductivity is mainly the result of a higher heat transfer rate. Therefore, in this study, a
\end{abstract}


saw-type corrugated tube was considered along with the $\mathrm{SiC}$-water nanofluid as the working fluid to determine the improvement of laminar convective heat transfer in terms of the Nusselt number, heat transfer coefficient, and pressure loss. The result demonstrated that by increasing the Reynolds number, the Nusselt number, heat transfer coefficient, and pressure loss were increased significantly with the enhancement of SiC-water concentration. At a Reynolds number of 1200, the maximum increment of Nusselt number in comparison to the base fluid was $9.15 \%$ when the corrugated pipe was considered. Meanwhile, the maximum improvement of heat transfer coefficient for SiC-water nanofluid in comparison to the base fluid was $37.66 \%$.

Keywords - Nusselt number; nanofluid; heat transfer coefficient; volume fraction; SiC nanoparticles; pressure loss.

\section{Graphical Abstract}

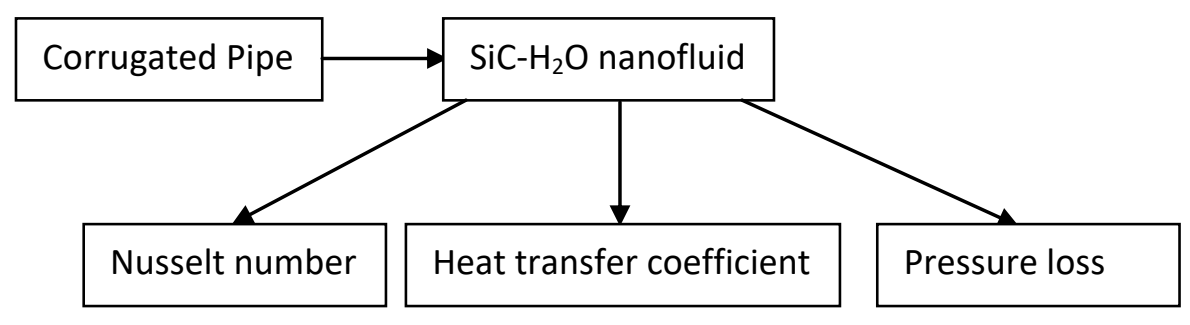

INTRODUCTION

The working fluids that are commonly utilized in heat transfer applications often reveal poor heat transfer performances. Therefore, it is crucial to look for enhanced heat transfer techniques. One potential technique in this regard is the utilization of corrugated pipe. The addition of appropriate metal or their oxide particles undoubtedly raises the heat transfer performance. Suspension of nanoparticles with base fluid and increment of the area of tube wall by applying corrugated wall section is relevantly more effective for heat transfer applications.

The enhancement of heat transmission via the use of corrugated channels has already been extensively studied during the past several decades. Various studies were undertaken on heat and 
mass transfer in corrugated channels. In the late 19th century, the concept of nanoparticles has become a significant part of modern adventure. During the 1980s, microchannel technology was introduced (Tuckerman \& Pease, 1981). Later, a new type of heat transfer fluid termed 'nanofluid' was proposed, and high thermal conductivity was found in the resulted nanofluids compared to other kinds of fluids (Choi \& Eastman, 1995). Meanwhile, heat transfer in the corrugated tube was investigated by utilizing a spiral wall of four-start, and it was found that the heat transmission was precisely proportionate to the index of severity (Smaisim, 2017). Moreover, the effectiveness of elliptical double corrugated tubes for thermal improvement was investigated, and it was identified that the fluid flow was affected noticeably, which modified the flow profile compared to the straight tube (Navickaite et al., 2019).

According to Abbas \& Dhaidan (2018), the effect of nanoparticle loading was comparatively more significant than the size of the nanoparticle and the pressure drop. In the meantime, thermal and hydraulic properties of nanofluid in circular ducts were observed by Hassanzadeh \& Tokgoz (2017), and it was found that the turbulent flow was developed in the entire ducts due to the application of periodic corrugations. Furthermore, a comparison of thermal performance of semicircle, trapezoidal, and house-shaped corrugated channels utilizing $\mathrm{ZnO}$ nanofluid was performed by Ajeel et al. (2019), which identified remarkable improvement of thermal performance. Additionally, corrugated tubes' internal flow for characterizing the heat transfer and pressure drop was observed by Andrade et al. (2019), and it was found that the effectiveness for maximum heat transfer augmentation was in the transitional flow regime as the Reynold number was close to 2000 .

Due to small thickness as well as capacity to be tuned through weight concentration variations, nanofluids may be regarded as a viable option to be used as spectrum filters (Ali, 2020). Besides, Shahsavar et al. (2021) worked with $\mathrm{Ag}-\mathrm{H}_{2} \mathrm{O}$ nanofluid and found that raising the 
quantity of connecting holes was beneficial in terms of the first-law standpoint; nevertheless, this was detrimental as per second-law. Meanwhile, nano- $\mathrm{Al}_{2} \mathrm{O}_{3}$ outperformed ordinary asphalt in terms of temperature reduction, whereas nano- $\mathrm{ZnO}$ cooled at the fastest pace (Qureshi et al., 2021). In addition, nanofluids can reduce waste generation, energy consumption, pollutants, as well as raw material utilization, thus minimizing environmental impact (Pordanjani et al., 2021). Moreover, according to Alqahtani et al. (2021), utilizing the scaling principle to obtain a highly integrated lattice structure can attain more excellent thermal resistance, which can be appropriate for energy-saving purposes. Furthermore, Ejaz et al. (2021) reviewed thermal management applications and several research works related to concentrated photovoltaics and suggested conducting more research in this field to identify more applications. Additionally, Parsa et al. (2021) investigated a salt-gradient solar pond and noticed its higher production capability. Recently, Rabby et al. (2021), Kusworo et al. (2020), Kumar et al. (2017), and several researchers conducted studies related to nanofluids due to the advancement of nanofluids.

Though various researchers worked on a corrugated pipe using nanofluids, no one highlighted the impact of SiC-water nanofluid especially for heat transfer application, which noticeably affects thermo-physical properties. Moreover, the maximum papers available in the literature analyzed turbulence heat transfer. Therefore, to provide further insight on this research, a saw type corrugated tube was considered along with $\mathrm{SiC}$-water nanofluid, which was introduced as the working fluid, to investigate the improvements of laminar convective heat transfer in terms of the Nusselt number and heat transfer coefficient as well as to determine the corresponding pressure loss. 


\section{METHODOLOGY}

\section{Physical Model}

Constant heat flux was supplied to both sides of a $2 \mathrm{D}$ tube to examine the rate of heat transfer. A computational experiment was undertaken utilizing ANSYS Fluent to examine nanofluid's flow properties via a pipe. The flow was assumed to be laminar, and the pipe was a 2D circular sharp pipe, length and radius of which were $750 \mathrm{~mm}$ and $2.5 \mathrm{~mm}$, respectively. The pipe wall boundary was subjected to a uniform constant heat flux of $500 \mathrm{~W} / \mathrm{m}^{2}$, and the pipe wall was considered to be in the no-slip state. The heat flux boundary condition was applied to the whole of the pipe's top section. At the pipe intake, boundary conditions such as constant temperature as well as inlet velocity were established to enable fluids to circulate at a constant temperature of $303 \mathrm{~K}$. The pressure outlet was used as the boundary condition at the pipe outlet. After hydrodynamic and thermal augmentation of the fluid stream, the heat exchange and fluid dynamics characteristics were released. Beyond the entry length of $x / D=60$, measurements were calculated. At the outlet, the bulk, as well as surface temperatures, were measured to determine the heat transmission parameters. Besides, thermal properties of $\mathrm{SiC}$ was checked and no visible sedimentation was noticed, which proved the stability of SiC particles.

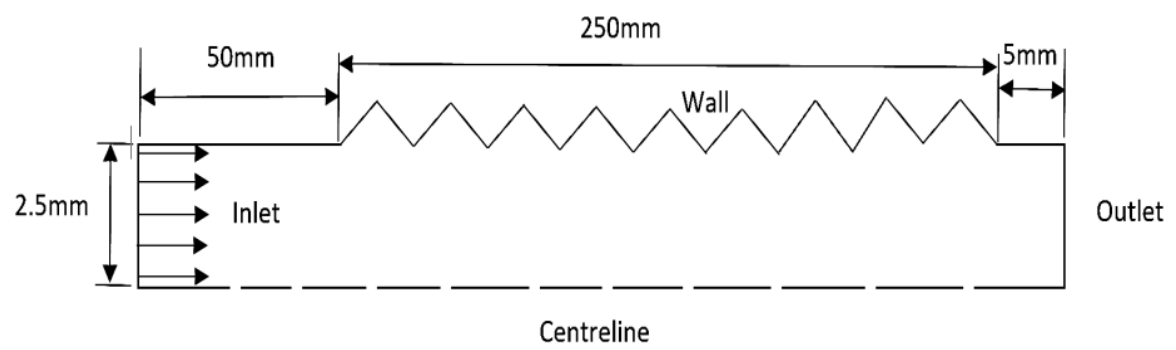

Figure 1. Schematic illustration of the physical model of the saw type corrugated pipe. 


\section{Numerical Method}

In order to discretize the governing equations and boundary conditions, a finite volume approach was utilized. Additionally, second-order upwind and second-order central differencing methods have been utilized for convective and diffusive terms, respectively. For coupling between pressure and velocity, a SIMPLE procedure has been applied.

\section{Governing Equations}

Continuity equation:

$$
\frac{\partial u}{\partial x}+\frac{\partial v}{\partial y}=0
$$

Here, $\boldsymbol{u}$ and $\boldsymbol{v}$ denote the fluid's velocity in the $\mathrm{x}$ and $\mathrm{y}$ directions, respectively.

Momentum equation:

$\mathrm{X}$-momentum equation,

$$
\rho\left(u \frac{\partial u}{\partial x}+v \frac{\partial v}{\partial y}\right)=-\frac{\partial p}{d x}+\mu\left(\frac{\partial^{2} u}{\partial x^{2}}+\frac{\partial^{2} u}{\partial y^{2}}\right)
$$

Y-momentum equation,

$$
\rho\left(u \frac{\partial v}{\partial x}+v \frac{\partial v}{\partial y}\right)=-\frac{\partial p}{d y}+\mu\left(\frac{\partial^{2} v}{\partial x^{2}}+\frac{\partial^{2} v}{\partial y^{2}}\right)
$$

Here, $\boldsymbol{\rho}$ and $\boldsymbol{\mu}$ denote the fluid's density and viscosity, respectively.

Energy equation:

$$
\rho_{n f} C_{P_{n f}}\left(u \frac{\partial T}{\partial x}+v \frac{\partial T}{\partial y}\right)=k_{n f}\left(\frac{\partial^{2} T}{\partial x^{2}}+\frac{\partial^{2} T}{\partial y^{2}}\right)
$$

Here, $\boldsymbol{T}, \boldsymbol{k}$, and $\boldsymbol{C}_{\boldsymbol{p}}$ denote the fluid's temperature, thermal conductivity, and specific heat at constant pressure, respectively.

For evaluating the efficacy of two passive techniques, the overall performance of primary conditions and enhanced conditions has been compared. 
Reynolds number equation of nanofluid:

$$
R e=\frac{\rho_{n f} U_{a v} D_{h}}{\mu_{n f}}
$$

Here, $\boldsymbol{D}_{\boldsymbol{h}}$ and $\boldsymbol{U}_{\boldsymbol{a}}$ denote the pipe's hydraulic diameter and average fluid velocity, respectively.

The equation for the heat transfer rate of nanofluid:

$$
Q_{n f}=m_{n f} C_{P_{n f}} \Delta T
$$

Here, $\Delta \boldsymbol{T}$ and $\boldsymbol{m}$ denote the temperature difference and mass flow rate, respectively.

The average heat transfer coefficient $\boldsymbol{h}_{c}$ is given by:

$$
h_{c}=\frac{Q_{n f}}{A_{w}(\Delta T)}
$$

Here, $\boldsymbol{A}_{\boldsymbol{w}}$ is pipe's surface area.

The equation for determining the temperature difference between the pipe and the wall:

$$
\Delta T=\frac{\left(T_{w}-T_{o}\right)-\left(T_{w}-T_{i}\right)}{\ln \left(\frac{T_{w}-T_{o}}{T_{w}-T_{i}}\right)}
$$

The average Nusselt number equation:

$$
N u=\frac{h_{c} D_{h}}{K_{n f}}
$$

Friction factor Darcy-Weisbach equation:

$$
f=\frac{64}{R e}
$$

Pressure loss equation:

$$
\Delta P=\frac{f L \rho U^{2}}{2 D_{k}}
$$




\section{Thermo Physical Properties of Nanofluids}

Dynamic Viscosity was calculated using the equation governed by Chen et al. (2007) for SiCwater as follows,

$$
\mu_{n f}=\mu_{b f}\left[1+10.6 \emptyset+(10.6 \emptyset)^{2}\right] \mu_{p}
$$

Thermal Conductivity was calculated according to Maxwell (1873) mode equation for all nanofluids, which is given by,

$$
K_{n f}=\frac{K_{p}+2 K_{b f}+2\left(K_{p}-K_{b f}\right) \emptyset}{K_{p}+2 K_{b f}-\left(K_{p}-K_{b f}\right) \emptyset} \times K_{b f}
$$

Density of nanofluids was calculated according to Xuan \& Roetzel (2000) equation,

$$
\rho_{n f}=\rho_{p} \emptyset+\rho_{b f}(1-\emptyset)
$$

Specific Heat of the nanofluids was measured following Pak \& Cho (2013) equation,

$$
C_{n f}=(1-\emptyset) C_{w}+\emptyset C_{p}
$$

Table 1. Thermofluidic properties of $\mathrm{H}_{2} \mathrm{O}$ and $\mathrm{SiC}$.

\begin{tabular}{|c|c|c|c|c|}
\hline Substance & Density & Specific heat & Thermal conductivity & Viscosity \\
$\left(\mathbf{k g} / \mathbf{m}^{\mathbf{3}}\right)$ & $(\mathbf{J} / \mathbf{k g} \cdot \mathbf{K})$ & $(\mathbf{W} / \mathbf{m} \cdot \mathbf{K})$ & $(\mathbf{k g} / \mathbf{m} . \mathbf{s})$ \\
\hline $\mathrm{H}_{2} \mathrm{O}$ & 996 & 4178 & 0.62 & 0.000798 \\
\hline $\mathrm{SiC}$ & 3220 & 750 & 120 & - \\
\hline
\end{tabular}

\section{Validation Test}

For validation, water was moved through the plain pipe at constant heat flux and uniform speed. Reynolds number within the range of 100-1000 was considered in order to obtain friction factor as well as Nusselt number. In a fully developed zone, a comparison was made among the local Nusselt number obtained from Shah and London's (1981) theoretical equation, shown in Figure 2(a). The findings showed a high degree of agreement with a maximum inaccuracy of $2 \%$ for the Nusselt number. Additionally, Figure 2(b) compares the friction factor calculated using 
the Darcy-Weisbach equation and obtained in the fully developed zone. It produces a negligible amount of inaccuracy. Furthermore, the pressure drop is defined by the friction factor. Whenever friction is increased, pressure drop increases proportionately. The correlation developed by Shah and London (1981) theoretical equation for the laminar tube can be expressed as follows,

$$
\begin{gathered}
\text { Nu }=1.302\left(\frac{x^{*}}{2}\right)^{-\left(\frac{1}{3}\right)}-0.5, x^{*} \leq 0.003 \\
N u=4.364+0.263\left(\frac{x^{*}}{2}\right)^{-0.506} e^{-41\left(\frac{x^{*}}{2}\right)}, x^{*}>0.03 \\
\text { Where, } \quad x^{*}=\frac{2(x / D)}{\operatorname{RePr}}
\end{gathered}
$$

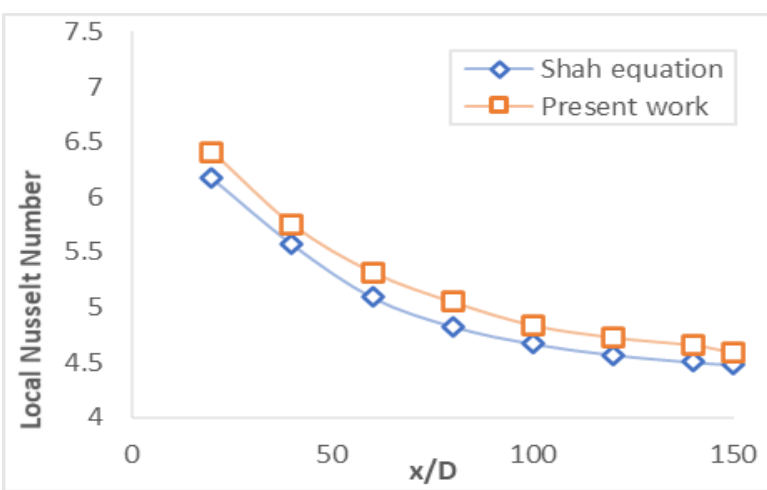

(a)

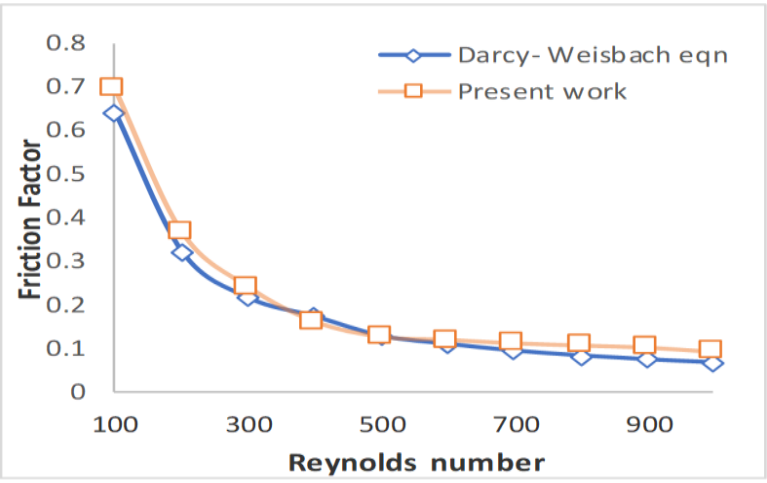

(b)

Figure 2. Comparison of (a) local Nusselt number of the study with Shah and London (1981) equation and (b) friction factor of the study with Darcy-Weisbach equation.

\section{Grid Refinement Test}

For the grid refinement study, water was used as the working material, and the simulation was performed at Reynolds number 600 for the plain pipe. To determine the optimal grid size of the current study, a grid refinement study was performed. Five diffident nodes were analyzed for determining the impact on the Nusselt number, which is exhibited in Figure 3. 


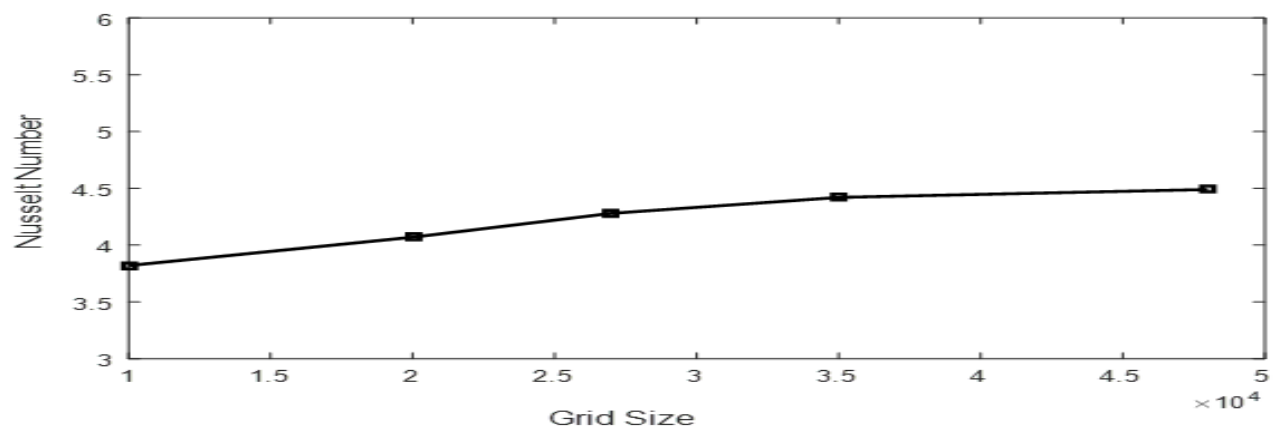

Figure 3. Nusselt Number variation with varied grid sizes.

According to Figure 3, no discernible variation in the Nusselt Number was visible above the grid size of 100035 , and the Nusselt number was very near to 4.36. As a result, all simulations in this research study were conducted with a grid size of 35000 .

Table 2. Mesh sensitivity analysis.

\begin{tabular}{|c|c|c|}
\hline Nodes & $\mathrm{Nu}$ & Deviation (\%) \\
\hline 20000 & 4.18 & - \\
\hline 25000 & 4.26 & 1.91 \\
\hline 32000 & 4.34 & 1.91 \\
\hline 35000 & 4.37 & 0.69 \\
\hline 38000 & 4.41 & 0.92 \\
\hline
\end{tabular}

RESULTS AND DISCUSSION

The effect of corrugation on Nusselt number and the heat transfer coefficient has been evaluated for water taken as base fluid by considering both plain and corrugated pipes. Fig. 4 and 5 demonstrate changes in Nusselt number and heat transfer coefficient, respectively, for the corrugated pipe in comparison to the plain pipe. It has been identified that Nusselt number and heat transfer coefficient increased up to $10.75 \%$ and $6.85 \%$, respectively, as a result of the increment of the net surface area of the corrugated pipe. 


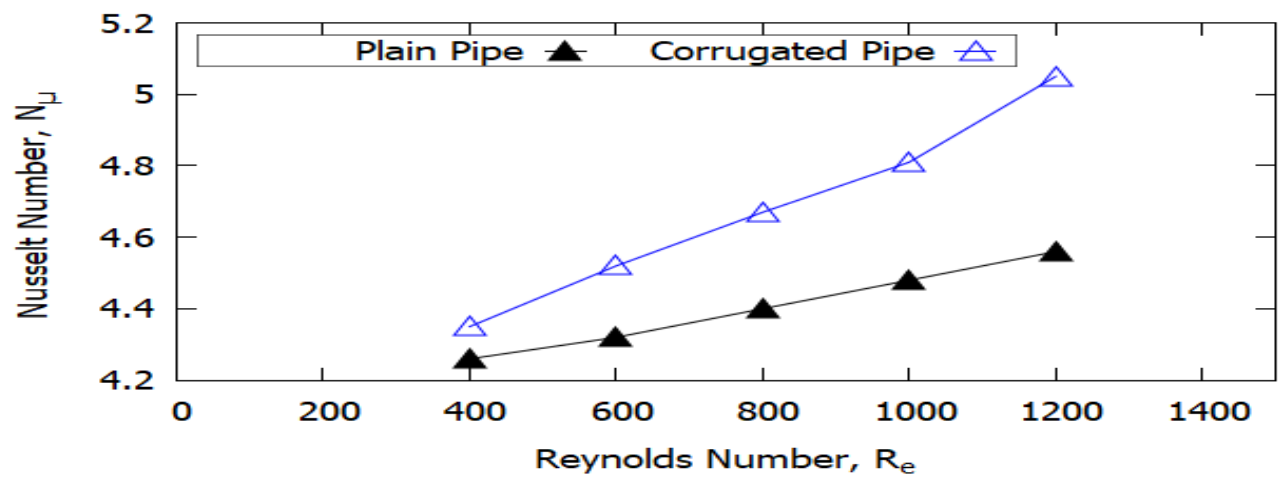

Figure 4. Enhancement in Nusselt number due to corrugation with water as working fluid.

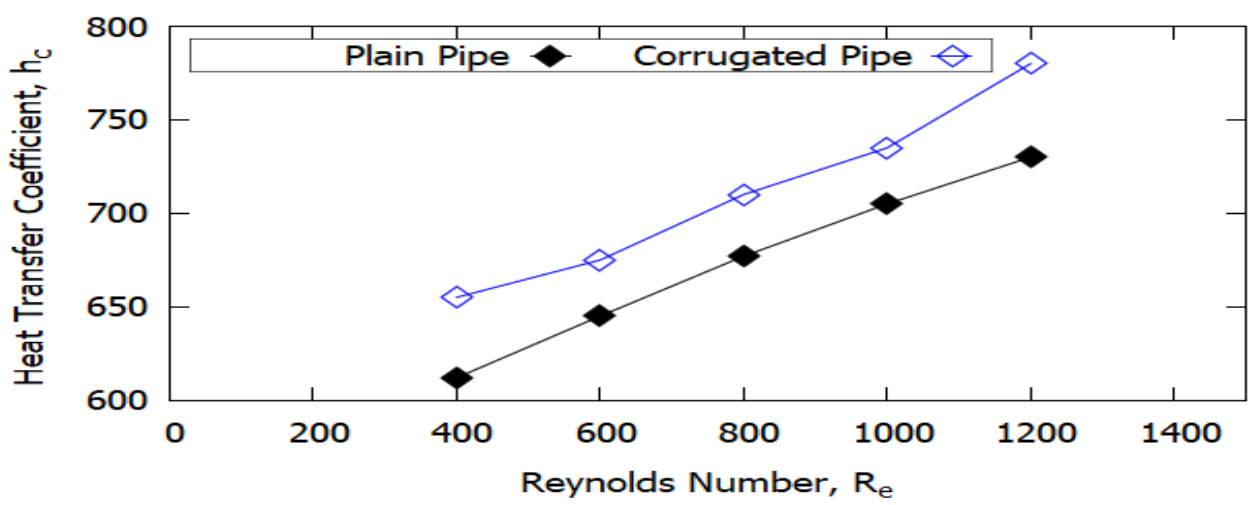

Figure 5. Increment of heat transfer coefficient $\left(\mathrm{W} / \mathrm{m}^{2} . \mathrm{K}\right)$ owing to the corrugation with water as working fluid.

The analysis considered $\mathrm{SiC}$-water nanofluid as the operating fluid across the semicircular domain with a $1 \%-5 \%$ volume fraction. With the increasing volume of nanofluid, the base fluid's thermal conductivity was improving, which resulted in an increment of the Nusselt number and the heat transfer rate for nanofluid. Figure 6 demonstrates variations of Nusselt number for SiCwater nanofluid, and Figure 7 illustrates the performance of heat transfer coefficient for the same nanofluid while using the corrugated pipe. The change also occurred owing to the rise of the Reynolds number for a fixed volume fraction of the nanofluid. For Reynolds number 1200, the maximum increment of Nusselt number was $9.15 \%$ for $5 \%$ SiC-water nanofluid. In contrast, the maximum enhancement of the heat transfer coefficient was $37.66 \%$ compared to the base fluid. 


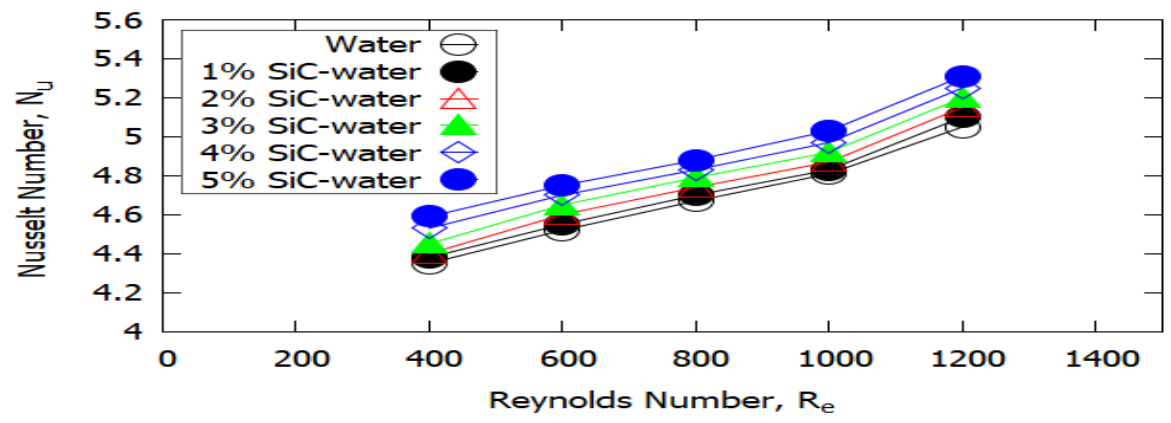

Figure 6. Variation of Nusselt number with Reynolds number.

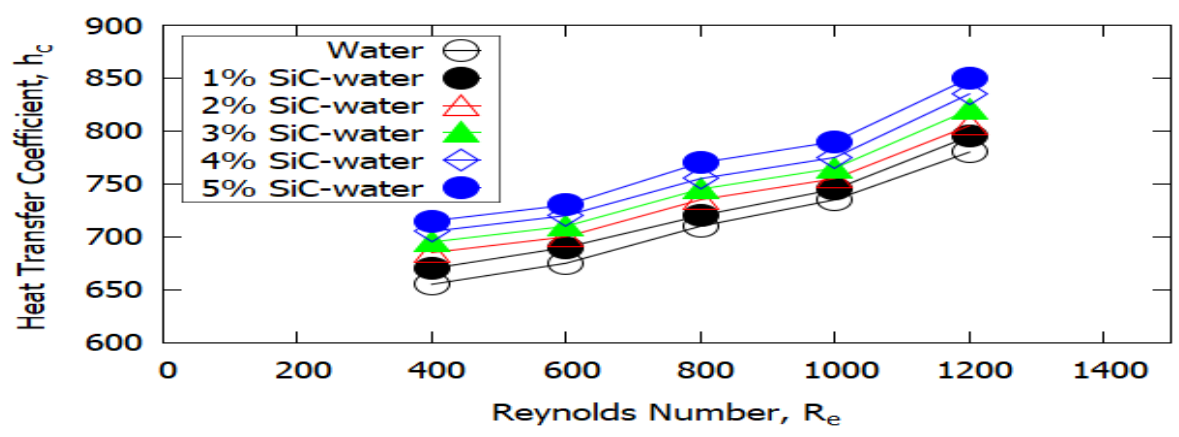

Figure 7. Variation of Heat transfer coefficient $\left(\mathrm{W} / \mathrm{m}^{2} . \mathrm{K}\right)$ with Reynolds number.

Moreover, when the volume fraction of nanofluid increases, the pressure loss rises owing to the working fluid's higher viscosity. The pressure loss also enhances with the increment of Reynolds number. Figure 8 represents the variation of pressure loss with volume fraction and Reynolds number for SiC-water nanofluid. For Reynolds number 1000, the enhancement of pressure loss was $11.84 \%$ for a $4 \%$ volume fraction of $\mathrm{SiC}$-water nanofluid.

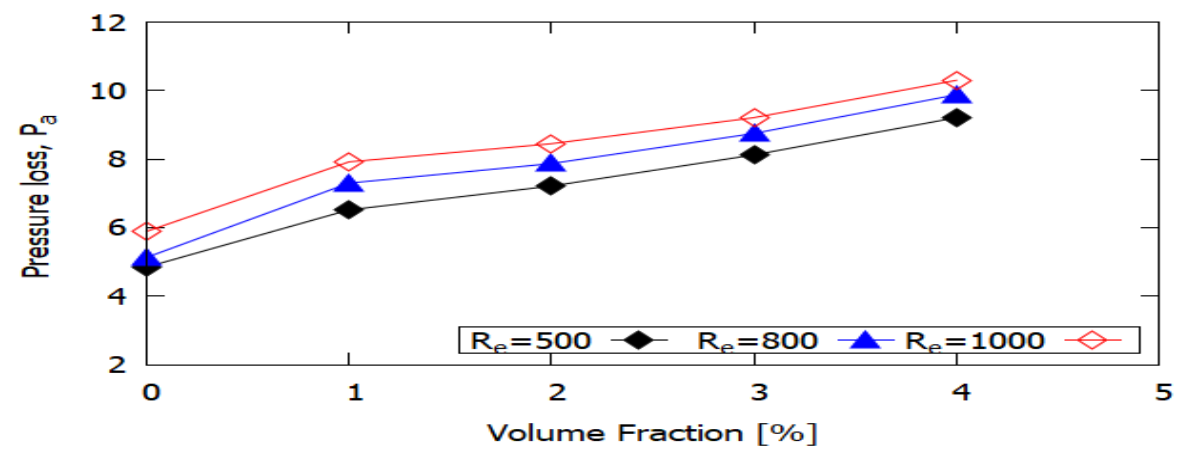

Figure 8. Variation of pressure loss $(\mathrm{Pa})$ with volume fraction and Reynolds number. 


\section{CONCLUSION}

This study considered saw-type corrugated pipes with nanofluids as the working fluids for improving the heat transfer performances. The key findings of this study were:

1. Corrugated pipe improved the coefficient of heat transfer and Nusselt number by up to $6.85 \%$ and $10.75 \%$, respectively, compared to the plain pipe.

2. SiC-water nanofluid showed a better heat transfer coefficient than water during flowing through corrugated pipe due to the higher thermal properties of nanofluids. The highest increment of the coefficient of heat transfer and Nusselt number was $37.66 \%$ and $9.15 \%$, respectively, for a 5\% SiC-water nanofluid at Reynolds number 1200.

3. This study also demonstrated that the pressure drop rises with the increment of the volume fraction of nanofluid and Reynolds number, owing to the increment of the viscosity of the working fluid. The maximum $11.84 \%$ increment of pressure loss was identified for a $4 \%$ SiCwater nanofluid and Reynolds number 1000.

\section{REFERENCES}

Abbas, A.K. \& Dhaidan, N.S. 2018. Turbulent forced convection of nanofluids flow in corrugated tubes. IOP Conference Series: Materials Science and Engineering 433(1): 012054.

Ajeel, R.K., Salim, W.I. \& Hasnan, K. 2019. Thermal performance comparison of various corrugated channels using nanofluid: Numerical study. Alexandria Engineering Journal 58(1): 75-87.

Ali, H.M. 2020. Recent advancements in PV cooling and efficiency enhancement integrating phase change materials based systems-A comprehensive review. Solar Energy 197: 163-198.

Alqahtani, S., Ali, H.M., Farukh, F., Silberschmidt, V.V. \& Kandan, K. 2021. Thermal performance of additively manufactured polymer lattices. Journal of Building Engineering 39: 102243. 
Andrade, F., Moita, A.S., Nikulin, A., Moreira, A.L.N. \& Santos, H. 2019. Experimental investigation on heat transfer and pressure drop of internal flow in corrugated tubes. International Journal of Heat and Mass Transfer 140: 940-955.

Chen, H., Ding, Y., He, Y. \& Tan, C. 2007. Rheological behaviour of ethylene glycol based titania nanofluids. Chemical physics letters 444(4-6): 333-337.

Choi, S.U. \& Eastman, J.A. 1995. Enhancing thermal conductivity of fluids with nanoparticles. International mechanical engineering congress and exhibition. Argonne National Lab, IL, United States.

Ejaz, A., Babar, H., Ali, H.M., Jamil, F., Janjua, M.M., Fattah, I.R., Said, Z. \& Li, C. 2021. Concentrated photovoltaics as light harvesters: Outlook, recent progress, and challenges. Sustainable Energy Technologies and Assessments 46: 101199.

Hassanzadeh, R. \& Tokgoz, N. 2017. Thermal-hydraulic characteristics of nanofluid flow in corrugated ducts. Journal of Engineering Thermophysics 26(4): 498-513.

Kumar, N., Jothi, T.S. \& Selvaraju, N. 2017. Effect of nanoparticle deposition rate on critical heat flux in pool boiling. Journal of Engineering Research 5(4): 305-323.

Kusworo, T.D., Budiyono, B., Qudratun, Q., Widodo, B. \& Prabowo, B.T. 2020. Enhancement of nano hybrid PES-nano silica performance for $\mathrm{CO}_{2} / \mathrm{CH}_{4}$ separation through combined UV irradiation and thermal annealing treatments. Journal of Engineering Research 8(3): 17-30.

Maxwell, J.C. 1873. A treatise on electricity and magnetism. Clarendon press, Oxford, United Kingdom.

Navickaitė, K., Cattani, L., Bahl, C.R. \& Engelbrecht, K. 2019. Elliptical double corrugated tubes for enhanced heat transfer. International Journal of Heat and Mass Transfer 128: 363-377. 
Pak, B.C. \& Cho, Y. 2013. Hydrodynamic and heat transfer study of dispersed fluid with submicron based $\mathrm{Al}_{2} \mathrm{O}_{3}$ and $\mathrm{CuO}$ nanofluids in a triangular duct. Journal of Dispersion Science and Technology 34: 1368-1375.

Parsa, S.M., Majidniya, M., Alawee, W.H., Dhahad, H.A., Ali, H.M., Afrand, M. \& Amidpour, M. 2021. Thermodynamic, economic, and sensitivity analysis of salt gradient solar pond (SGSP) integrated with a low-temperature multi effect desalination (MED): Case study, Iran. Sustainable Energy Technologies and Assessments 47: 101478.

Pordanjani, A.H., Aghakhani, S., Afrand, M., Sharifpur, M., Meyer, J.P., Xu, H., Ali, H.M., Karimi, N. \& Cheraghian, G. 2021. Nanofluids: Physical phenomena, applications in thermal systems and the environment effects-a critical review. Journal of Cleaner Production 320: 128573.

Qureshi, F.A., Ahmad, N. \& Ali, H.M. 2021. Heat dissipation in bituminous asphalt catalyzed by different metallic oxide nanopowders. Construction and Building Materials 276: 122220.

Rabby, M.I.I., Hossain, F., Amin, S.S. \& Islam, A.S. 2021. Numerical simulation on performance evaluation among metal and oxide based nanofluids for power savings application of a circular tube. Journal of Thermal Engineering 7(5): 1150-1162.

Shah, R.K. \& London, A.L. 1978. Laminar flow forced convection in ducts. Supplement 1 to Advances in Heat Transfer. Academic Press, New York, United States.

Shahsavar, A., Entezari, S., Askari, I.B. \& Ali, H.M. 2021. The effect of using connecting holes on heat transfer and entropy generation behaviors in a micro channels heat sink cooled with biological silver/water nanofluid. International Communications in Heat and Mass Transfer 123: 104929.

Smaisim, G.F. 2017. Augmentation of Heat Transfer in Corrugated Tube Using Four-Start Spiral Wall. Al-Qadisiyah Journal for Engineering Sciences 10(4): 451-467. 
Tuckerman, D.B. \& Pease, R.F.W. 1981. High-performance heat sinking for VLSI. IEEE Electron device letters 2(5): 126-129.

Xuan, Y. \& Roetzel, W. 2000. Conceptions for heat transfer correlation of nanofluids. International Journal of heat and Mass transfer 43(19): 3701-3707. 